\title{
Gray Matter Volume Correlates of Sleepiness: A Voxel-Based Morphometry Study in Younger and Older Adults
}

\author{
Torbjörn Åkerstedt ${ }^{1,2}$ \\ Mats Lekander ${ }^{1,2}$ \\ Gustav Nilsonne (iD) 1,2 \\ Sandra Tamm (D) ${ }^{1,2}$ \\ Paolo d'Onofrio ${ }^{1,2}$ \\ Göran Kecklund ${ }^{1,2}$ \\ Håkan Fischer ${ }^{3}$ \\ Johanna Schwarz ${ }^{1,2}$ \\ Predrag Petrovic' \\ Kristoffer NT Månsson (iD) ${ }^{4-6}$ \\ 'Department of Clinical Neuroscience, \\ Karolinska Institutet, Stockholm, Sweden; \\ ${ }^{2}$ Stress Research Institute, Department \\ of Psychology, Stockholm University, \\ Stockholm, Sweden; ${ }^{3}$ Department of \\ Psychology, Stockholm University, \\ Stockholm, Sweden; ${ }^{4}$ Centre for \\ Psychiatry Research, Department of \\ Clinical Neuroscience, Karolinska \\ Institutet, Stockholm, Sweden; ${ }^{5}$ Center \\ for Lifespan Psychology, Max Planck \\ Institute for Human Development, Berlin, \\ Germany; ${ }^{6}$ Max Planck UCL Centre for \\ Computational Psychiatry and Ageing \\ Research, Berlin, Germany
}

This article was published in the following Dove Press journal: Nature and Science of Sleep

\begin{abstract}
Background: Subjectively experienced sleepiness is a problem in society, possibly linked with gray matter (GM) volume. Given a different sleep pattern, aging may affect such associations, possibly due to shrinking brain volume.

Purpose: The purpose of the present study was to investigate the association between subjectively rated sleepiness and GM volume in thalamus, insula, hippocampus, and orbitofrontal cortex of young and older adults, after a normal night's sleep.

Methods: Eighty-four healthy individuals participated (46 aged 20-30 years, and 38 aged 65-75 years). Morphological brain data were collected in a 3T magnetic resonance imaging (MRI) scanner. Sleepiness was rated multiple times during the imaging sessions.

Results: In older, relative to younger, adults, clusters within bilateral mid-anterior insular cortex and right thalamus were negatively associated with sleepiness. Adjustment for the immediately preceding total sleep time eliminated the significant associations.

Conclusion: Self-rated momentary sleepiness in a monotonous situation appears to be negatively associated with GM volume in clusters within both thalamus and insula in older individuals, and total sleep time seems to play a role in this association. Possibly, this suggests that larger GM volume in these clusters may be protective against sleepiness in older individuals. This notion needs confirmation in further studies.
\end{abstract}

Keywords: brain imaging, thalamus, insula, sleep, KSS

\section{Introduction}

The subjective experience of sleepiness represents a feeling of exhaustion ${ }^{1}$ and/or an effort to remain awake. ${ }^{2}$ It is associated with changes in the EEG pattern, eye movements, performance capacity and accident risk. ${ }^{3}$ The main regulatory factors are amount of prior sleep, ${ }^{4}$ quality of sleep (fragmentation), ${ }^{5}$ time since prior sleep, and time of day. ${ }^{6}$

Sleepiness is clearly expressed in the working brain, ${ }^{7}$ and this raises the question whether there also may be links to brain morphology. From a theoretical standpoint, the thalamus is of major interest for a study of subjective sleepiness and GM volume because of its key role in regulation of arousal and vigilance. ${ }^{8}$ In addition, Poudel et $\mathrm{al}^{9}$ showed that thalamic activity was reduced during microsleep episodes, as well as activity in midbrain areas, posterior cingulate cortex (PCC), and occipital areas. Also, Olbrich et al found reduced thalamic activity during lower vigilance EEG states. ${ }^{10}$ In the only study of ratings of sleepiness and thalamic activity, Maire et al showed a parallel development of less activity in thalamus and higher KSS values. ${ }^{11}$
Correspondence: Torbjörn Åkerstedt Department of Clinical Neuroscience, Karolinska Institutet, Stockholm 17177, Sweden

Email torbjorn.akerstedt@ki.se 
Another theoretically interesting structure in this context is the insular cortex, since its anterior part is associated with awareness of internal states ${ }^{12}$ and is a central node in a network of regions that form an intrinsic interoceptive network. ${ }^{13}$ More specifically, it has been proposed that the anterior part is associated with subjective experiences, including feeling states and emotional awareness. $^{12}$ Thus, one might argue that the subjective experience of sleepiness may be seen as a feeling state based on interoceptive input from various biological systems in need of sleep. No empirical support is available, however.

While the studies above suggest that thalamus and insula should be likely starting points for investigating the link between subjective sleepiness and GM volume under conditions of normal sleep, they have been focused on activation in the structures, not volume. The only studies of sleepiness and actual GM volume found a negative association for a cluster in the orbitofrontal cortex $^{14}$ and the hippocampus. ${ }^{15}$

A number of studies have investigated BOLD activation during performance tasks after, or during, sleep deprivation. In these studies, structures like the dorsolateral prefrontal cortex (DLPFC) and the intraparietal sulcus usually show reduced task-related activation after sleep loss. ${ }^{16-20}$ However, the regions being affected by severe sleep loss may not necessarily be the same ones that are involved in sleepiness in well-rested individuals, and we have, therefore, not included such structures among our regions of interest.

A study of sleepiness and brain morphology should also consider aging as a possible moderator since sleepiness decreases with aging, ${ }^{21,22}$ as does the thickness of the cortex. ${ }^{23}$ This suggests that a lower gray matter (GM) volume may be associated with less sleepiness across age groups. However, this contrasts with the previously mentioned negative association for a cluster in the orbitofrontal cortex ${ }^{14}$ and hippocampus. ${ }^{15}$ The latter studies did not consider age, however. Higher age is also associated with shorter sleep, ${ }^{24}$ which contrasts with the association of lower sleepiness with higher age. These, somewhat incommensurate, observations indicate the need for considering also age and sleep duration when investigating sleepiness and GMV.

The purpose of the present study was to investigate the link between self-reported momentary subjectively experienced sleepiness in the MR scanner and brain morphology in younger and older adults, as measured by GM volume in the thalamus, anterior insula, orbitofrontal cortex, and hippocampus after a full night's sleep. We also tested whether age would modify observed associations. The main hypothesis is a negative association between GM volume and sleepiness in the orbitofrontal cortex and hippocampus. Albeit preliminary, this may also be valid for thalamus and anterior insula GM volume. The present study is part of the Stockholm Sleepy Brain Project focusing on sleep restriction, polysomnography, and brain imaging. . $^{256}$

\section{Methods}

\section{Design}

The participants underwent a night of full sleep and a night of partial sleep deprivation in a balanced cross-over design. Sleep was monitored by polysomnography (PSG) in both conditions. ${ }^{27}$ The present paper presents the MRI data from the full sleep condition. For increased ecological validity, sleep recordings were carried out in the participants' homes. MRI was performed in the evening following the recorded sleep (approximately between 18:00 and 21:00). The evening was selected in order to use also the time awake during the day as an inducer of sleepiness. All participants provided written informed consent and the trial was conducted in accordance with the Declaration of Helsinki.

\section{Participants}

The participants were recruited through posters on campus sites in Stockholm on the studentkaninen.se website, and in newspaper ads, ${ }^{28}$ The responders were first screened through an online questionnaire and then followed up with an interview. The exclusion criteria were ferromagnetic items in body, claustrophobia, being pregnant, refractive error exceeding 5 diopters, being color-blind, being left-handed, psychiatric (including depression; score $>8$ for anxiety or depression on the Hospital Anxiety and Depression Scale $(\mathrm{HADS})^{29}$ ) or neurological illness, addiction, hypertension, diabetes, use of psychoactive or immune-modulatory drugs, use of nicotine every day, $>4$ cups of coffee per day, insomnia (Insomnia Severity Index $>15^{30}$ ), extreme morningness or eveningness (using a single item from the diurnal type scale, ${ }^{31}$ including a habitual bedtime before $1 \mathrm{am}$ ). Furthermore, sleep apnea was identified through finger plethysmographic recording during the sleep preceding the MRI scan. Those with sleep apnea were excluded from further analyses. The criterion for inclusion was set to $\leq 5$ events/h of oxygen desaturation $>3 \%$. Moreover, the participants should not study, or have studied, medicine or psychology, to avoid individuals prone to metacognitions while undergoing experiments. Table 1 shows the demographic and clinical variables. The participants were also 
Table I Background Data for the Two Age Groups, and ANOVA Results for the Difference Between Groups

\begin{tabular}{|l|l|l|l|l|}
\hline & $\begin{array}{l}\text { Young } \\
\text { Mean } \\
\pm \text { SD }\end{array}$ & $\begin{array}{l}\text { Older } \\
\text { Mean } \\
\pm \text { SD }\end{array}$ & $\boldsymbol{F}$ & $\boldsymbol{P}$ \\
\hline $\mathrm{N}$ & 42 & 42 & & \\
Age & $23.8 \pm 2.6$ & $68.6 \pm 2.6$ & & \\
BMI & $22.9 \pm 3.14$ & $24.5 \pm 3.36$ & 4.7 & 0.033 \\
Subjective health (I-7) & $4.58 \pm 0.54$ & $4.67 \pm 0.54$ & 0.5 & 0.463 \\
Women \% & $52 \%$ & $47 \%$ & 0.2 & 0.850 \\
HADS anxiety & $3.02 \pm 2.5$ & $I .33 \pm 1.4$ & 13.3 & 0.001 \\
HADS depression & $1.20 \pm 1.37$ & $I .14 \pm 0.99$ & 0.1 & 0.750 \\
ISI & $10.6 \pm 2.1$ & $9.1 \pm 1.6$ & 13.9 & 0.001 \\
KSQ (I-6) & $5.26 \pm 0.42$ & $5.23 \pm 0.50$ & 0.1 & 0.798 \\
Enough sleep (I-6) & $4.1 I \pm 0.74$ & $4.56 \pm 0.50$ & 9.4 & 0.003 \\
Sleep need (h) & $7.86 \pm 0.88$ & $7.39 \pm 0.85$ & 5.8 & 0.018 \\
Habitual sleep duration & $8.53 \pm 1.30$ & $8.22 \pm 1.30$ & 1.1 & 0.290 \\
(h) & & & & \\
Recorded sleep (TST, h) & $6.6 I \pm 1.30$ & $7.16 \pm I .40$ & 6.05 & 0.017 \\
\hline
\end{tabular}

Abbreviations: N, number of participants; KSQ, Karolinska Sleep Questionnaire ISI, Insomnia Severity Scale (see below for details); HADS, Hospital Anxiety and Depression Scale; BMI, body mass index; TST, total sleep time (from polysomnography); h, hours; F, F-ratio; p, p-value for statistical significance.

required to understand and speak Swedish fluently and to live in the greater Stockholm area. In total, 84 individuals were included in the final neuroimaging analyses (young, $n=46$; older, $\mathrm{n}=38$ ). For a detailed description of the included and excluded participants, see https://openarchive.ki.se/xmlui/han dle/10616/45181. The participants were paid SEK 2500 (approximately EUR 280/USD 360), which was subject to tax. They were also offered a taxi to and from the MRI center.

\section{MRI Acquisition and Preprocessing}

A General Electric Discovery 3 Tesla MRI scanner equipped with an 8-channel head coil was used. The T1weighted anatomical scan was acquired with a sagittal BRAVO sequence, field of view $24 \mathrm{~cm}$, slice thickness $1 \mathrm{~mm}$, TI $450 \mathrm{~ms}$, flip angle 11, matrix 240x240, 180 slices, $\mathrm{TR}=6.4 \mathrm{~ms}, \mathrm{TE}=2.8 \mathrm{~ms}$, interleaved acquisition from bottom up. The MRI acquisition session started with a 4 minute anatomical T1-scan, followed by functional MRI scans totaling approx. 1 hour, and it ended by structural scan (T2 and diffusion tensor imaging). Structural and functional imaging data are available at https://openfmri.org/dataset/ds000201.

After a visual inspection of the raw T1-image, voxel-based morphometry (VBM) was run using the computational anatomy toolbox version 12 (CAT12; http://dbm.neuro.uni-jena. de/cat12) implemented in the statistical parametric mapping version 12 (SPM12; http://www.fil.ion.ucl.ac.uk/spm). The T1-weighted images were subject to spatial registration, segmentation, and correction for bias, noise and intensity (default parameters). All of the images were normalized to Montreal Neurological Institute (MNI) template space with $1.5 \mathrm{~mm}$ isotropic voxels. Sample homogeneity was checked on all 84 VBM images and no outlier was found. Subsequently, in line with the CAT12 toolbox manual, images were smoothed with a full-width at half maximum kernel of $8 \mathrm{~mm}$.

\section{Self-Ratings}

For descriptive purposes, we used several rating scales: The Karolinska Sleep Questionnaire (KSQ), ${ }^{32}$ contains a sleep quality index of 4 items describing the frequency of having difficulties falling asleep, premature awakenings, restless sleep, and frequent awakenings. The response alternatives ranged from never (6) to almost all days of the week (1). Items such as difficulties falling asleep, repeated awakenings, restless sleep, and premature awakening were combined into a sleep quality index. In the present study, items on "enough sleep" (6=always, 1=never), need for sleep (h), and habitual sleep duration were also used. The Insomnia Severity Scale (ISI) contains 8 questions on sleep problems. ${ }^{33}$ Subjective health was rated on a 1-7 scale, from very poor to very good. In addition, The Hospital Anxiety and Depression scale $^{29}$ was used. The latter has a cut-off point for clinical cases at $8 .{ }^{34}$

The session included 7 tasks: a structural scan, resting state, 3 tasks with different types of visual stimuli of emotional character (emotional mimicry, empathy for pain, and emotional reappraisal), followed by a new resting state, and a structural scan. Between the 8 sessions in the scanner, the participants were prompted through the visual presentation system to rate their sleepiness (at 7 time points) using a hand-held response panel to move a cursor to the appropriate response. The 7 points were then averaged for analysis. The scale was the Karolinska Sleepiness Scale (KSS). ${ }^{2,3}$ This is a single-item question with 9 ordinal anchored response alternatives, ranging from $1=$ very alert to $9=$ very sleepy, fighting sleep, an effort to keep awake). Self-reported sleepiness has been reported in a previous paper on the polysomnography the night before the MR recording. ${ }^{27}$ However, since the sample in the present study differed slightly from the previous one, due to MRI restrictions, the KSS values (means across the 7 time points acquired during the MRI) are also presented here. 


\section{Polysomnography}

Polysomnography was recorded the night before each session in the scanner. The recordings were made according to standard procedure ${ }^{35}$ and scored according to standard criteria. ${ }^{36}$ The results have been presented in Åkerstedt et al. ${ }^{27}$ Here, total sleep time (TST) is used as a covariate.

\section{Data Analysis}

Data analyses on self-ratings and polysomnography were performed using the STATA Statistical Software, v. 15.0 (STATA, College Station, TX, USA). Quality checked and preprocessed brain images were entered into second level statistical analyses in SPM12. One- and two-sample $t$-tests with covariates (see below), ie total intracranial volume (TIV) and KSS, were used in the following models. Design orthogonality was checked, and it was suggested that TIV correlated to KSS. Therefore, in accordance with the CAT12 manual, we used the global scaling transformation on intracranial volume (ie overall grand mean scaling). Absolute threshold masking was set at 0.006 to differentiate between gray and white matter.

Small volume correction was performed within selected regions using the corresponding function in SPM12, ie each anatomically defined region independently. We also performed conservative post hoc tests with small volume correction including all ROIs simultaneously (see Figure 1). In alignment with Malone et al, ${ }^{37}$ each subject's total intracranial volume was entered as a nuisance variable in all subsequent analyses. Furthermore, the symptoms of depression and anxiety were entered as covariates without interest since they correlate with sleepiness and represent potential confounders. ${ }^{38}$

All structural ROIs were defined bilaterally since we had no hypotheses on laterality. Based on previous VBM studies on GM volume and sleep (for more details, see introduction), the following four ROIs were defined: insular cortex, frontal superior orbitofrontal cortex/gyrus rectus, ${ }^{14}$ hippocampus, ${ }^{15}$ and thalamus, ${ }^{39}$ as defined by the Automated Atlas Labeling atlas from the Wake Forest University PickAtlas. ${ }^{40,41}$ The significance threshold level inside ROIs was set at $P<.05$ with a family-wise error (FWE) correction. The voxel-wise whole-brain analyses were reported with uncorrected $\alpha$ set at $\leq .001$, and a cluster threshold was also set at $51 \mathrm{~mm}^{3}$ (equals 15 voxels). Whole-brain regional clusters surviving false discovery rate $(\mathrm{FDR})(P<.05)$ were considered significant.

\section{Results \\ Age Differences in Sleepiness and GM Volume}

Self-rated sleepiness differed between the two age groups, mean \pm sd KSS $=5.33 \pm 1.5$ for young adults and $4.58 \pm 1.4$ for older adults $(\mathrm{t}(85)=2.38, \mathrm{P}=.019)$. GM volume in clusters in all of the ROIs was smaller in older individuals compared to younger ones $\left(Z>4.95, P^{F W E}<.001\right)$.

\section{KSS and GM Volume}

The association between KSS and GM volume (with the age group as a covariate of no interest) was not significant in any ROI $\left(P^{\mathrm{FWE}}>.420\right.$ for negative associations and $P^{\mathrm{FWE}}>.569$ for positive associations).

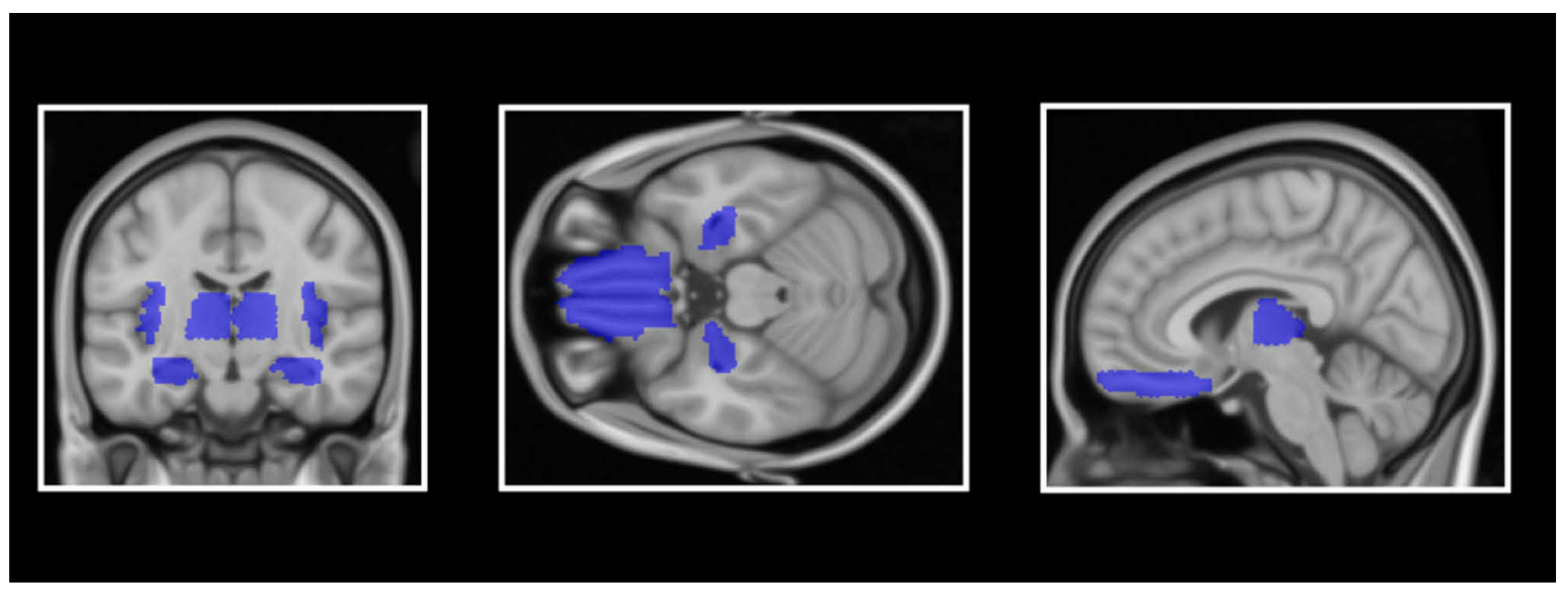

Figure I Demonstration of anatomically defined regions of interest (ROls): insula cortex, hippocampus, frontal superior orbitofrontal cortex/rectus gyrus and thalamus. 


\section{Age Differences (Interactions) in KSS-Associated GM Volume}

In older, relative to younger adults, the clusters within the bilateral insular cortex and thalamus regions of interest were negatively associated with sleepiness (Table 2, Figures 2 and 3 ). In a fully adjusted small volume correction including all of the ROIs simultaneously, the age-interaction effects (negative associations in the older group, and no associations in the younger group) were significant in clusters in the bilateral insula (left: $P^{\mathrm{FWE}}=0.044$; right: $P^{\mathrm{FWE}}=.026$ ) and right thalamus $\left(P^{\mathrm{FWE}}=.005\right)$ but not in the left thalamus $\left(P^{\mathrm{FWE}}=0.111\right)$. Interestingly, the clusters were located in the mid-anterior insula. Third, in contrast to our expectations, we did not find an interaction effect between the age group and KSS on GM volume in the hippocampus or the frontal superior orbitofrontal cortex/gyrus rectus.

For completeness, exploratory voxel-wise whole-brain analyses on the main effect of age on sleepiness-associated GM volume are presented in Table 3. In Table 4 both groups are combined. After whole-brain cluster-level correction, we found no significant associations $\left(P^{\mathrm{FDR}}>.05\right)$.

Given that KSS was related to depressive symptoms in younger adults, and that anxiety symptoms differed between

Table 2 Age Group Interactions of Associations Between Sleepiness (KSS Scores) and GM Volume

\begin{tabular}{|c|c|c|c|c|c|}
\hline $\begin{array}{l}\text { Region of } \\
\text { Interest } \\
\text { (ROI) }\end{array}$ & $\begin{array}{l}\text { Age } \\
\text { Effect }\end{array}$ & $\begin{array}{l}\text { MNI } \\
(x, y, \\
z)\end{array}$ & $\mathbf{Z}$ & $\begin{array}{l}\text { Voxels } \\
\left(\mathrm{mm}^{3}\right)\end{array}$ & $P^{F W E}$ \\
\hline$L$ insula & $\begin{array}{l}\text { Interaction } \\
\mathrm{Y}+\mathrm{O}-\end{array}$ & $\begin{array}{l}-34 \\
8,-15\end{array}$ & 4.02 & 6605 & 0.015 \\
\hline$R$ insula & $\begin{array}{l}\text { Interaction } \\
\mathrm{Y}+\mathrm{O}-\end{array}$ & $\begin{array}{l}32,9,- \\
18\end{array}$ & 4.42 & 5947 & 0.009 \\
\hline $\begin{array}{l}\text { L Sup OFC/ } \\
\text { rectus gyrus }\end{array}$ & $\begin{array}{l}\text { Interaction } \\
\mathrm{Y}+\mathrm{O}-\end{array}$ & $\begin{array}{l}-10 \\
20,-14\end{array}$ & 2.16 & $\infty$ & 0.895 \\
\hline $\begin{array}{l}\text { R Sup OFCI } \\
\text { rectus gyrus }\end{array}$ & $\begin{array}{l}\text { Interaction } \\
\mathrm{Y}+\mathrm{O}-\end{array}$ & $\begin{array}{l}8,21,- \\
20\end{array}$ & 2.18 & $227 I$ & 0.884 \\
\hline L hippocampus & $\begin{array}{l}\text { Interaction } \\
\mathrm{Y}+\mathrm{O}-\end{array}$ & $\begin{array}{l}-24,- \\
22,-16\end{array}$ & 3.12 & 2457 & 0.149 \\
\hline R hippocampus & $\begin{array}{l}\text { Interaction } \\
\mathrm{Y}+\mathrm{O}-\end{array}$ & $\begin{array}{l}15,- \\
32,9\end{array}$ & 3.17 & 2977 & 0.131 \\
\hline$L$ thalamus & $\begin{array}{l}\text { Interaction } \\
\mathrm{Y}+\mathrm{O}-\end{array}$ & $\begin{array}{l}-15,- \\
22,2\end{array}$ & 3.75 & 3068 & 0.020 \\
\hline $\mathrm{R}$ thalamus & $\begin{array}{l}\text { Interaction } \\
\mathrm{Y}+\mathrm{O}-\end{array}$ & $\begin{array}{l}20,- \\
26,4\end{array}$ & 4.60 & 4074 & 0.001 \\
\hline
\end{tabular}

Notes: $\mathrm{Y}+$ indicates a positive association in younger adults, and $\mathrm{O}-$ indicatesnegative association in older adults. ${ }^{\infty}$ Effects seen in left and right hemisphere belongs to the same cluster of GM volume; bold= significant $p$-values. $x, y, z=$ coordinates. Abbreviations: GM, gray matter; MNI, Montreal Neurological Institute; L, left; $R$, right; Sup OFC, frontal superior orbitofrontal cortex; FWE, family wise-error correction; KSS, Karolinska Sleepiness Scale. age groups (see below), we entered HADS Depression and HADS Anxiety scores as covariates of no interest in two separate models. In the fully adjusted analysis including all of the ROIs, age interactions on KSS were still seen in clusters in left $\left(P^{\mathrm{FWE}}=.048\right)$ and right insula $\left(P^{\mathrm{FWE}}=.028\right)$ as well as in right thalamus $\left(P^{\mathrm{FWE}}=.005\right)$ after adjusting for depression and anxiety. Similarly, sex and BMI were entered as covariates of no interest, and the age interactions on KSS and GM volumes were maintained $\left(P^{\mathrm{FWE}}<.041\right)$ in clusters in the bilateral insula and the right thalamus $\left(P^{\mathrm{FWE}}<.041\right)$. After adding TST as a covariate of no interest, no significant age interaction on GM volume remained in any of the ROIs $\left(P^{\mathrm{FWE}}>.097\right)$.

\section{Within-Groups Analyses}

Brain regions demonstrating a significant age interaction effect were also analyzed within each age group separately. We found that thalamus GM volume was negatively associated with older adults' sleepiness, both in the left (xyz [-16, -22, 3], $\mathrm{Z}=3.49, P^{\mathrm{FWE}}=.046$, cluster size $\left.=3878 \mathrm{~mm} 3\right)$ and right $(\mathrm{xyz}$ $[21,-26,6], Z=4.11, P^{\mathrm{FWE}}=.006$, cluster size $=5501 \mathrm{~mm}^{3}$ ) hemisphere. At trend, older adults' insula GM volume was negatively associated with sleepiness (right insula: $Z=3.65$, $P^{\mathrm{FWE}}=.054$; left insula: $\left.\mathrm{Z}=3.51, P^{\mathrm{FWE}}=.084\right)$. The positive association between GM volume and sleepiness (found as an age group interaction effect) was not significant in the younger group alone (thalamus: $Z<2.85, P^{\mathrm{FWE}}>.241$; insula: $\mathrm{Z}<3.45$, $P^{\mathrm{FWE}}>$.102).

\section{Hospital Anxiety and Depression Scale}

Depressive symptoms, as determined by the HADS Depression subscale, did not differ between younger and older adults. Nevertheless, KSS was positively associated with depressive symptoms in younger adults (Pearson's $r=0.29, P=.046)$, but not in older adults $(r=0.22$, $P=.178$ ). In addition, anxiety symptoms (HADS Anxiety subscale) were higher in younger relative to older individuals. However, they were not associated with KSS in younger or older adults $(r<0.03, P>.83)$.

\section{Discussion}

The results showed that sleepiness, as well as thalamic and insular GM volume, was lower in older adults. The association between GM volume and sleepiness was not significant across age groups, however. We also found an interactive association of age and sleepiness in right thalamus and bilateral insula GM volume. In the older group, sleepiness decreased significantly with increasing GM volume in clusters in thalamus and at trend in insula, 

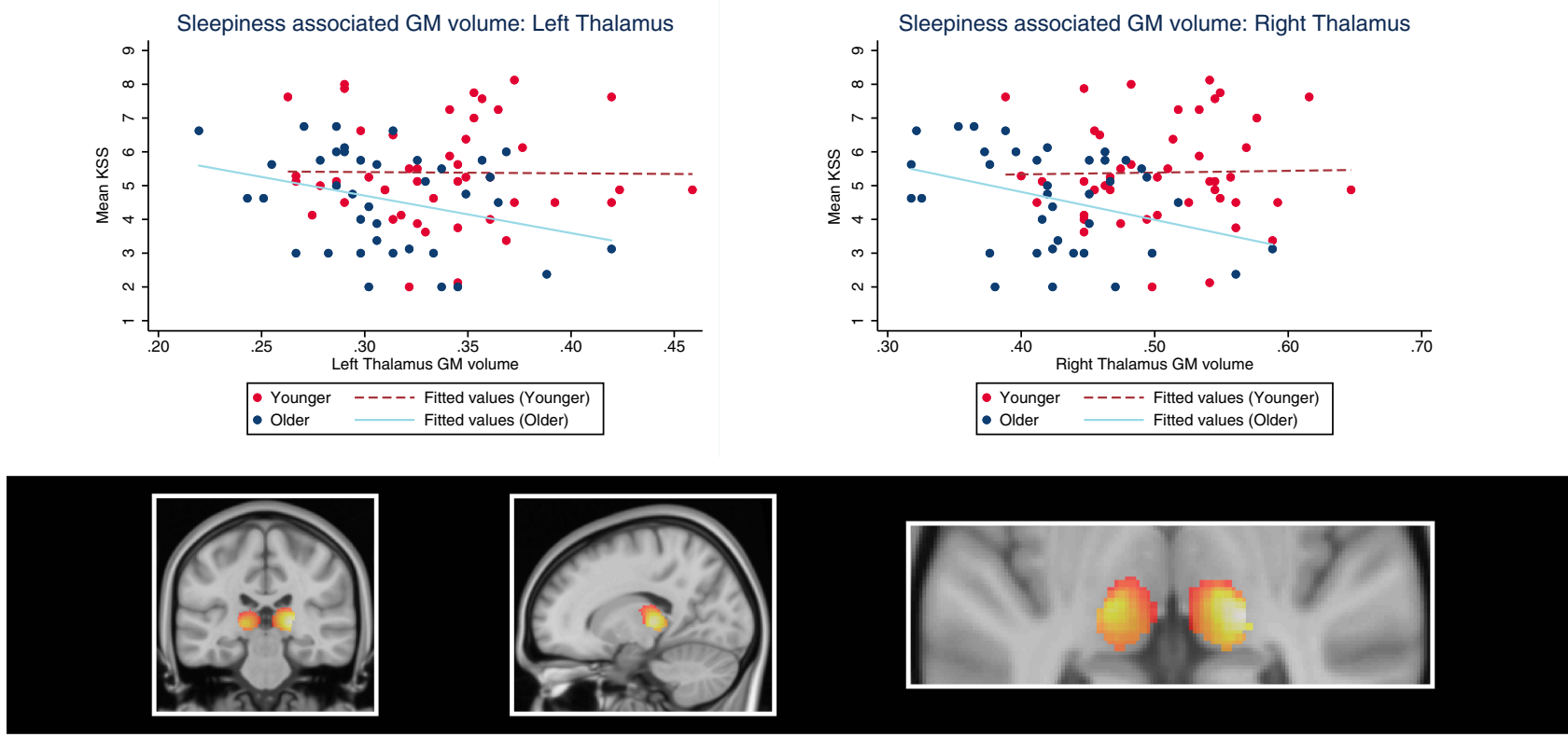

Figure 2 Demonstration of sleepiness (KSS scores)-associated thalamic gray matter volume in younger and older adults. The plots show the age interaction effect suggesting that sleepiness is negatively associated with left and right thalamus gray matter volume in older adults, but positively associated in younger individuals. The colors in the brain plot represent statistical $t$-values ranging from 0 (black) to 5.0 (white).

Abbreviation: KSS, Karolinska Sleepiness Scale.

while there was no significant association in the young group. These associations were modified after adjusting for gender and BMI, and were eliminated after adjusting for the TST of the immediately preceding sleep.
With regard to the first finding, there is no previous work on reported sleepiness and GM volume across age groups, but the results agree with the observations of lower sleepiness in older individuals, ${ }^{21,42}$ on the one hand, and
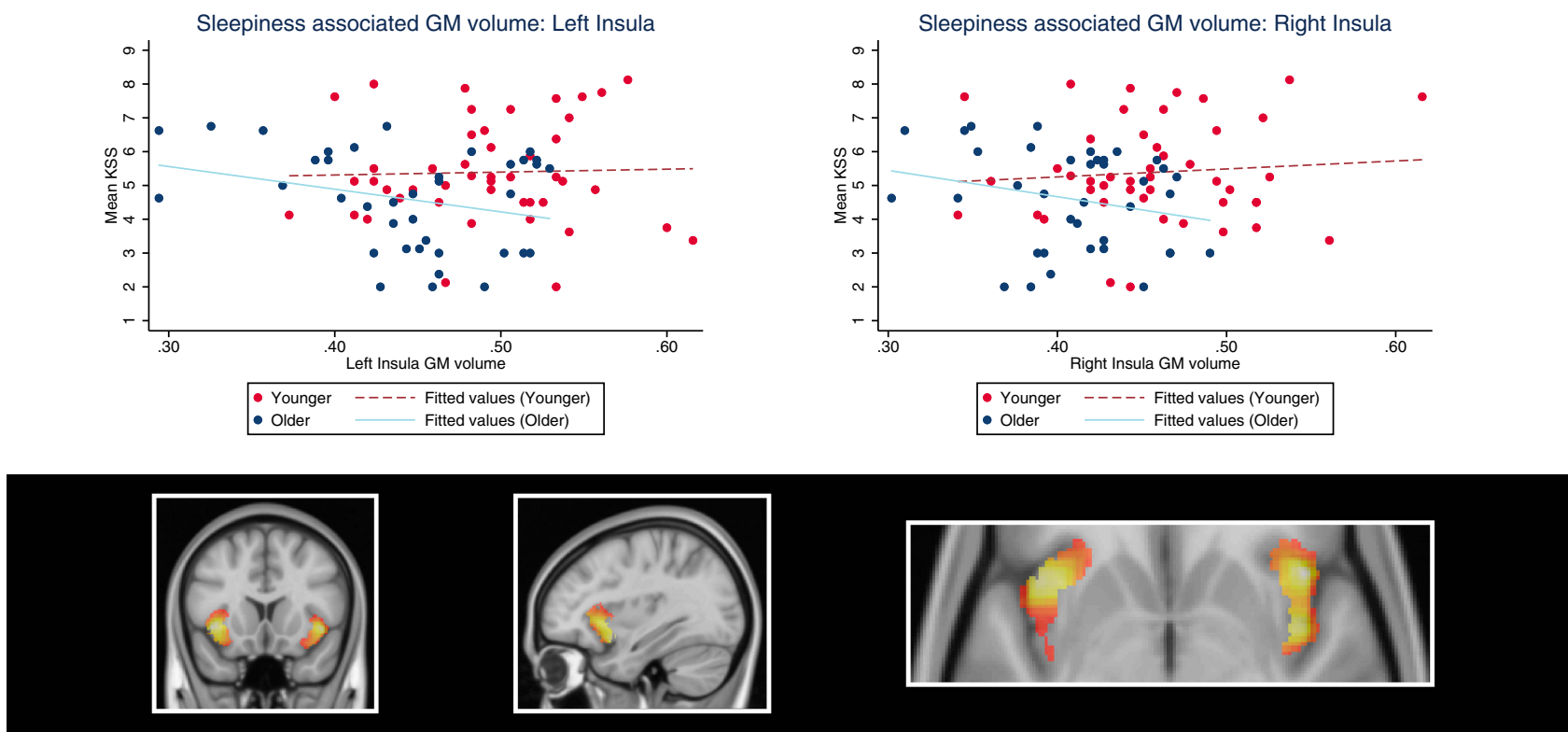

Figure 3 Demonstration of sleepiness (KSS scores)-associated insula gray matter volume in younger and older adults. The plots show the age interaction effect suggesting that sleepiness is positively associated with left and right insula gray matter volume in younger adults, but negatively associated in older individuals. The colors in the brain plot represent statistical $t$-values ranging from 0 (black) to 4.5 (white).

Abbreviation: KSS, Karolinska Sleepiness Scale. 
Table 3 Exploratory Whole-Brain Analyses on Age Group Interactions of Associations Between Sleepiness (KSS Scores) and GM Volume

\begin{tabular}{|c|c|c|c|c|c|}
\hline Region & $\begin{array}{l}\text { Age } \\
\text { Effect }\end{array}$ & $\begin{array}{l}\text { MNI } \\
(x, y, \\
z)\end{array}$ & $Z$ & $\begin{array}{l}\text { Voxels } \\
\left(\mathrm{mm}^{3}\right)\end{array}$ & $\begin{array}{l}P \\
\text { (Uncorr) }\end{array}$ \\
\hline $\mathrm{R}$ thalamus & $\begin{array}{l}\text { Interaction } \\
\mathrm{Y}+\mathrm{O}-\end{array}$ & $\begin{array}{l}20,- \\
26,4\end{array}$ & 4.60 & 1485 & $<.001$ \\
\hline$R$ insula & $\begin{array}{l}\text { Interaction } \\
\mathrm{Y}+\mathrm{O}-\end{array}$ & $\begin{array}{l}32, \\
8,- \\
18\end{array}$ & 4.35 & 1593 & $<.001$ \\
\hline$L$ insula & $\begin{array}{l}\text { Interaction } \\
\mathrm{Y}+\mathrm{O}-\end{array}$ & $\begin{array}{l}-34, \\
8,- \\
16\end{array}$ & 4.28 & 2228 & $<.001$ \\
\hline$R$ insula & $\begin{array}{l}\text { Interaction } \\
\mathrm{Y}+\mathrm{O}_{-}\end{array}$ & $\begin{array}{l}44, \\
16,- \\
6\end{array}$ & 4.09 & 378 & $<.001$ \\
\hline L cerebellum & $\begin{array}{l}\text { Interaction } \\
\mathrm{Y}+\mathrm{O}-\end{array}$ & $\begin{array}{l}- \\
18,- \\
74,- \\
48\end{array}$ & 4.01 & 1529 & $<.001$ \\
\hline $\mathrm{R}$ cerebellum & $\begin{array}{l}\text { Interaction } \\
\mathrm{Y}+\mathrm{O}_{-}\end{array}$ & $\begin{array}{l}46,- \\
74- \\
32\end{array}$ & 3.83 & 1232 & $<.001$ \\
\hline$L$ thalamus & $\begin{array}{l}\text { Interaction } \\
\mathrm{Y}+\mathrm{O}-\end{array}$ & $\begin{array}{l}- \\
15,- \\
22,2\end{array}$ & 3.75 & 270 & $<.001$ \\
\hline R postcentral & $\begin{array}{l}\text { Interaction } \\
\mathrm{Y}+\mathrm{O}-\end{array}$ & $\begin{array}{l}39,- \\
34, \\
58\end{array}$ & 3.60 & 250 & $<.001$ \\
\hline $\mathrm{R}$ cerebellum & $\begin{array}{l}\text { Interaction } \\
\mathrm{Y}+\mathrm{O}-\end{array}$ & $\begin{array}{l}8,- \\
48,- \\
36\end{array}$ & 3.36 & 95 & $<.001$ \\
\hline $\begin{array}{l}\text { L parietal } \\
\text { superior }\end{array}$ & $\begin{array}{l}\text { Interaction } \\
\mathrm{Y}+\mathrm{O}-\end{array}$ & $\begin{array}{l}- \\
27,- \\
62, \\
44\end{array}$ & 3.36 & 139 & $<.001$ \\
\hline $\mathrm{R}$ cerebellum & $\begin{array}{l}\text { Interaction } \\
\mathrm{Y}+\mathrm{O}-\end{array}$ & $\begin{array}{l}26,- \\
78,- \\
54\end{array}$ & 3.32 & 422 & $<.001$ \\
\hline
\end{tabular}

Notes: $\mathrm{Y}+$ indicates positive association in younger adults, and $\mathrm{O}-$ indicatesnegative association in older adults.

Abbreviations: GM, gray matter; MNI, Montreal Neurological Institute; L, left; $R$, right; KSS, Karolinska Sleepiness Scale; Uncorr, uncorrected. $x, y, z=$ coordinates.

with observations of lower GM volume in older individuals, ${ }^{23}$ on the other hand. Still, the association in the present study between GM volume and sleepiness was not significant for the two age groups combined. One reason may be that the difference in sleepiness between the age groups is rather modest ( $0.75 \mathrm{KSS}$ units), even if significant. This may, in turn, be related to the screening procedure, in which individuals in good health and without
Table 4 Exploratory Whole-Brain Main Effects of Associations Between Sleepiness (KSS Scores) and GM Volume for Both Groups Together.

\begin{tabular}{|c|c|c|c|c|c|}
\hline Region & $\begin{array}{l}\text { Age } \\
\text { Effect }\end{array}$ & $\begin{array}{l}\text { MNI } \\
(x, y, \\
z)\end{array}$ & $\mathbf{Z}$ & $\begin{array}{l}\text { Voxels } \\
\left(\mathrm{mm}^{3}\right)\end{array}$ & P (Uncorr) \\
\hline $\begin{array}{l}\mathrm{R} \text { frontal mid } \\
\text { orbitofrontal }\end{array}$ & $\begin{array}{l}\text { Main } \\
\text { YO+ }\end{array}$ & $\begin{array}{l}22, \\
52,- \\
10\end{array}$ & 3.52 & 135 & $<.001$ \\
\hline L cerebellum & $\begin{array}{l}\text { Main } \\
\text { YO- }\end{array}$ & $\begin{array}{l}-12,- \\
58,- \\
62\end{array}$ & 4.21 & 1225 & $<.001$ \\
\hline $\mathrm{R}$ cerebellum & $\begin{array}{l}\text { Main } \\
\text { YO- }\end{array}$ & $\begin{array}{l}28,- \\
84,- \\
39\end{array}$ & 3.83 & 425 & $<.001$ \\
\hline $\begin{array}{l}\text { L rolandic } \\
\text { operculum }\end{array}$ & $\begin{array}{l}\text { Main } \\
\text { YO- }\end{array}$ & $\begin{array}{l}-45,- \\
6,4\end{array}$ & 3.72 & 246 & $<.001$ \\
\hline $\mathrm{R}$ cerebellum & $\begin{array}{l}\text { Main } \\
\text { YO- }\end{array}$ & $\begin{array}{l}15,- \\
57,- \\
63\end{array}$ & 3.69 & 516 & $<.001$ \\
\hline
\end{tabular}

Notes: $\mathrm{YO}+$ and $\mathrm{YO}-$ indicate the sign of the (+, positively; -, negatively) across both age groups. $x, y, z=$ coordinates.

Abbreviations: GM, gray matter; MNI, Montreal Neurological Institute; L, left; R, right; KSS, Karolinska Sleepiness Scale; Uncorr, uncorrected.

All of the Ps are Presented at an uncorrected level.

sleep problem were selected. This needs to be considered in future studies.

The second finding, of a negative association between sleepiness and GM volume in thalamus and insula, in the older group, agrees in terms of direction with the negative association with sleepiness (using the ESS) found for GM volume of a cluster in the orbitofrontal $\operatorname{cortex}^{14}$ and hippocampus. ${ }^{15}$ We could not, however, confirm the findings for the latter two regions. One reason could be that those studies used the Epworth Sleepiness Scale which describes habitual sleepiness. The latter may not be representative of the momentary sleepiness measured in the present study.

The findings for thalamus are also in line with the notion that this structure is a regulator of brain arousal. ${ }^{8}$ Also, recently Månsson et $\mathrm{al}^{43}$ reported that an individual's mental state affects indices of GM volume. It remains speculative at this point, but it could be that older individuals' thalamic and insula brain morphometrics are sensitive to momentary sleepiness.

The third finding was the interaction between sleepiness related insula (bilaterally) GM volume, and age. The pattern was the same as for thalamic clusters: a negative association at trend in the older group, and no significant association in the younger group. Much of the reasoning 
regarding the thalamus can probably be applied similarly to the insula, although the insula does not have the arousal regulatory role that the thalamus has. Rather, the link between sleepiness and insula seems logical from the role of the insula as a center for awareness of the state of the organism ${ }^{12}$ and its role in the intrinsic interoceptive network that controls and represents the autonomic and hormonal systems in the body. ${ }^{13}$ While the posterior insula has been associated with the representation of interoceptive input, it has been suggested that the anterior insula is more related to subjective feeling states. ${ }^{12}$ Because sleepiness is measured as a subjective rating, it is of interest that the observed interaction is present in the mid-anterior insula and that the ability to recognize heartbeats, for example, is positively related to the volume of the anterior insula. ${ }^{44}$ Moreover, it has been suggested that a smaller insula is linked to a lower top-down regulatory capacity of information processing in insula, ${ }^{45-48}$ which may be in line with the negative correlation trend between sleepiness and insula volume in the older group. This interpretation suggests that the insula findings may reflect the subjective awareness of the arousal level of the thalamus, possibly due to a dampened regulatory capacity of insula. We have previously reported that older participants in this dataset have lower regional homogeneity (ReHo) in bilateral insula compared to the younger participants. ${ }^{25}$ One possible unifying explanation could be that agerelated vascular changes cause a loss of autoregulatory function in the vascular bed, leading to reduced ReHo and tissue shrinkage.

The observation that adjusting for TST eliminated the significant associations between GM volume and sleepiness in the older group may implicate a possible mechanism. This needs replication, and the finding indicates that the relation between TST, GM volume, and sleepiness should be investigated further. Another limitation of the present study is its cross-sectional character, which precludes causal inference, and does not exclude cohort effects. A sample across all ages would have made it possible to better understand whether a negative relation between GM volume and sleepiness reflects a gradual development across age.

Furthermore, a limitation may be that sleepiness ratings were obtained from the time in the MRI scanner. No ratings were obtained earlier during the same day. We do not know whether the obtained ratings represent whole day ratings of sleepiness. Most likely they do not, since the situation in the scanner is soporific - lying down with dimmed lighting and carrying out relatively monotonous tasks. Apparently, intrusions of sleep are common, ${ }^{49}$ although in the present study's eye monitoring showed that longer eye closures did not occur during fMRI runs. We suggest, therefore, that the obtained ratings represent a susceptibility to sleepiness in a monotonous situation and that the results should be interpreted in that light.

In conclusion, the present study suggests that self-rated momentary sleepiness in a monotonous situation may be negatively associated with GM volume in clusters within thalamus, and possibly insula, in older individuals. A tentative interpretation is that larger thalamic and insulae GM volume may be protective against sleepiness in older individuals, but further investigation is needed, not the least given the negative result of the whole-brain analyses. However, the present results should be interpreted with caution and replication studies could further knowledge in the much-needed area of understanding determinants of sleepiness, and in extension, the puzzling relations between age, sleep need and experiences of sleepiness.

\section{Data Sharing Statement}

The project was preregistered at https://clinicaltrials.gov/ ct2/show/NCT02000076 and approved by the Ethics Review board of the Stockholm region (Dnr 2012/1098-31/2). Methods, data, and technical validation have been reported in detail in a previous manuscript. ${ }^{28}$ All data are available immediately and indefinitely from the openneuro.org repository, doi: 10.18112/openneuro. ds000201.v1.0.3. We share the full deidentified imaging data set. Other data or documents may be obtained on request from the first author.

\section{Acknowledgments}

This work was supported by the Tercentenary Fund of Bank of Sweden, the Swedish Brain Foundation, The Swedish Science Council, the Fredrik and Ingrid Thuring Foundation, the AFA insurance company, and Stockholm Stress Center. We are grateful to Diana Cortes, Danielle Cosme and Roberta Nagai for assistance with polysomnography recordings, to Birgitta Mannerstedt Fogelfors for assistance with screening and instructions to participants, to Rouslan Sitnikov and Jonathan Berrebi for assistance with MRI sequences and auxiliary equipment, and to Hannes Ingre for entering sleep diary data into a spreadsheet. An abstract of this paper was presented as 
a poster presentation with interim findings at the 2018 Conference in Baltimore of the Associated Professional Sleep Societies. The poster's abstract was published as abstract 0149, page A58 in the journal SLEEP, April 1, 2018 (Oxford Academic Press/Sleep Research Society). https://doi-org.proxy.kib.ki.se/10.1093/sleep/zsy061.148

\section{Author Contributions}

All authors made substantial contributions to conception and design, acquisition of data, analysis and interpretation of data, drafting the manuscript, revising the manuscript critically, read and approved the final draft of the manuscript for submission, gave final approval of the manuscript version to be published, and agreed to be accountable for every step of the work published, and agreed to be accountable for all aspects of the work.

\section{Disclosure}

None of the authors have declared any conflicts of interest.

\section{References}

1. Hoddes E, Zarcone V, Smythe H, Phillips R, Dement W. Quantification of sleepiness: a new approach. Psychophysiol. 1973;10(4):431-436. doi:10.1111/j.1469-8986.1973.tb00801.x

2. Akerstedt T, Gillberg M. Subjective and objective sleepiness in the active individual. International $J$ Neurosci. 1990;52(1-2):29-37. doi: 10.3109/00207459008994241

3. Akerstedt T, Anund A, Axelsson J, Kecklund G. Subjective sleepiness is a sensitive indicator of insufficient sleep and impaired waking function. J Sleep Res. 2014;23(3):240-252. doi:10.1111/jsr.12158

4. Härmä M, Suvanto S, Popkin S, Pulli K, Mulder M, Hirvonen K. A dose-response study of total sleep time and the ability to maintain wakefulness. J Sleep Res. 1998;7(3):167-174. doi:10.1046/j.13652869.1998.00115.x

5. Bonnet MH, Arand DL. Clinical effects of sleep fragmentation versus sleep deprivation. Sleep Med Rev. 2003;7(4):297-310. doi:10.1053/ smrv.2001.0245

6. Fröberg JE. Twenty-four hour patterns in human performance, subjective and physiological variables and differences between morning and evening active subjects. Biol Psychol. 1977;5:119-134. doi:10.1016/0301-0511(77)90008-4

7. Ma N, Dinges DF, Basner M, Rao H. How acute total sleep loss affects the attending brain: a meta-analysis of neuroimaging studies. Sleep. 2015;38(2):233-240. doi:10.5665/sleep.4404

8. Schiff ND. Central thalamic contributions to arousal regulation and neurological disorders of consciousness. Ann $N$ Y Acad Sci. 2008;1129(1):105-118. doi:10.1196/annals.1417.029

9. Poudel GR, Jones RD, Innes CR, Watts R, Signal TL, Bones PJ. fMRI correlates of behavioural microsleeps during a continuous visuomotor task. Conf Proc 31st IEEE Eng Med Biol Soc. 2009;2009:2919-2922.

10. Olbrich S, Mulert C, Karch S, et al. EEG-vigilance and BOLD effect during simultaneous EEG/fMRI measurement. Neuroimage. 2009;45 (2):319-332. doi:10.1016/j.neuroimage.2008.11.014

11. Maire M, Reichert CF, Gabel V, et al. Human brain patterns underlying vigilant attention: impact of sleep debt, circadian phase and attentional engagement. Sci Rep. 2018;8(1):970. doi:10.1038/s41598017-17022-9
12. Craig AD. How do you feel-now? The anterior insula and human awareness. Nat Rev Neurosci. 2009;10(1):59-70. doi:10.1038/ nrn2555

13. Barrett LF, Simmons WK. Interoceptive predictions in the brain. Nat Rev Neurosci. 2015;16(7):419-429. doi:10.1038/nrn3950

14. Killgore WD, Schwab ZJ, Kipman M, DelDonno SR, Weber M. Voxel-based morphometric gray matter correlates of daytime sleepiness. Neurosci Lett. 2012;518(1):10-13. doi:10.1016/j. neulet.2012.04.029

15. Sforza E, Celle S, Saint-Martin M, Barthelemy JC, Roche F. Hippocampus volume and subjective sleepiness in older people with sleep-disordered breathing: a preliminary report. J Sleep Res. 2016;25(2):190-193. doi:10.1111/jsr.12367

16. Chee MW, Goh CS, Namburi P, Parimal S, Seidl KN, Kastner S. Effects of sleep deprivation on cortical activation during directed attention in the absence and presence of visual stimuli. Neuroimage. 2011;58(2):595-604. doi:10.1016/j.neuroimage.2011.06.058

17. Chee MW, Tan JC. Lapsing when sleep deprived: neural activation characteristics of resistant and vulnerable individuals. Neuroimage. 2010;51(2):835-843. doi:10.1016/j.neuroimage.2010.02.031

18. Chee MW, Tan JC, Zheng H, et al. Lapsing during sleep deprivation is associated with distributed changes in brain activation. J Neurosci. 2008;28(21):5519-5528. doi:10.1523/JNEUROSCI.0733-08.2008

19. Chee MW, Chuah LY, Venkatraman V, Chan WY, Philip P, Dinges DF. Functional imaging of working memory following normal sleep and after 24 and $35 \mathrm{~h}$ of sleep deprivation: correlations of fronto-parietal activation with performance. Neuroimage. 2006;31 (1):419-428. doi:10.1016/j.neuroimage.2005.12.001

20. Krause AJ, Simon EB, Mander BA, et al. The sleep-deprived human brain. Nat Rev Neurosci. 2017;18(7):404-418. doi:10.1038/ nrn.2017.55

21. Lowden A, Anund A, Kecklund G, Peters B, Akerstedt T. Wakefulness in young and elderly subjects driving at night in a car simulator. Acc Anal Prev. 2009;41(5):1001-1007. doi:10.1016/j. aap.2009.05.014

22. Akerstedt T, Hallvig D, Kecklund G. Normative data on the diurnal pattern of the Karolinska Sleepiness Scale ratings and its relation to age, sex, work, stress, sleep quality and sickness absence/illness in a large sample of daytime workers. J Sleep Res. 2017;26(5):559-566. doi: $10.1111 /$ jsr. 12528

23. Dube J, Lafortune $\mathrm{M}$, Bedetti $\mathrm{C}$, et al. Cortical thinning explains changes in sleep slow waves during adulthood. $J$ Neurosci. 2015;35 (20):7795-7807. doi:10.1523/JNEUROSCI.3956-14.2015

24. Ohayon MM, Carskadon MA, Guilleminault C, Vitiello MV. Metaanalysis of quantitative sleep parameters from childhood to old age in healthy individuals: developing normative sleep values across the human lifespan. Sleep. 2004;27(7):1255-1273. doi:10.1093/sleep/ 27.7.1255

25. Nilsonne G, Tamm S, Schwarz J, et al. Intrinsic brain connectivity after partial sleep deprivation in young and older adults: results from the Stockholm Sleepy Brain study. Sci Rep. 2017;7(1):9422. doi:10.1038/s41598-017-09744-7

26. Tamm S, Nilsonne G, Schwarz J, et al. The effect of sleep restriction on empathy for pain: an fMRI study in younger and older adults. Sci Rep. 2017;7(1):12236. doi:10.1038/s41598-017-12098-9

27. Akerstedt T, Lekander M, Nilsonne G, et al. Effects of late-night short-sleep on in-home polysomnography: relation to adult age and sex. J Sleep Res. 2018;27(4):e12626. doi:10.1111/jsr.12626

28. Nilsonne G, Tamm S, d'Onofrio P, et al. A multimodal brain imaging dataset on sleep deprivation in young and old humans; 2016. Available from: http://openarchivekise/xmlui/handle/10616/45181. Accessed May 15, 2020.

29. Zigmond AS, Snaith RP. The Hospital Anxiety and Depression Scale. Acta Psychiat Scand. 1983;67(6):361-370. doi:10.1111/j.16000447.1983.tb09716.x 
30. Bastien C, Vallieres A, Morin C. Validation of the Insomnia Severity Index as an outcome measure for insomnia research. Sleep Med. 2001;2(4):297-307. doi:10.1016/S1389-9457(00)00065-4

31. Torsvall L, Åkerstedt T. A diurnal type scale. Scand J Work Environ Health. 1980;6(4):283-290. doi:10.5271/sjweh.2608

32. Akerstedt T, Ingre M, Broman JE, Kecklund G. Disturbed sleep in shift workers, day workers, and insomniacs. Chronobiol Int. 2008;25 (2-3):333-348. doi:10.1080/07420520802113922

33. Morin CM, Belleville G, Belanger L, Ivers H. The Insomnia Severity Index: psychometric indicators to detect insomnia cases and evaluate treatment response. Sleep. 2011;34(5):601-608. doi:10.1093/sleep/ 34.5.601

34. Bjelland I, Dahl AA, Haug TT, Neckelmann D. The validity of the Hospital Anxiety and Depression Scale. An updated literature review J Psychosom Res. 2002;52(2):69-77. doi:10.1016/S0022-3999(01) 00296-3

35. Rechtschaffen A, Kales A. A manual of standardized terminology, techniques and scoring system for sleep stages of human subjects. Bethesda: US Department of Health, Education and Welfare, Public Health Service; 1968.

36. Iber C, Ancoli-Israel S, Chesson A, Quan S, Medicine ftAAoS. The AASM Manual for the Scoring of Sleep and Associated Events: Rules, Terminology and Technical Specifications, 1st edition. Westchester: American Academy of Sleep Medicine;2007.

37. Malone IB, Leung KK, Clegg S, et al. Accurate automatic estimation of total intracranial volume: a nuisance variable with less nuisance. Neuroimage. 2015;104:366-372. doi:10.1016/j.neuroimage.2014.09.034

38. Fernandez-Mendoza J, Vgontzas AN, Kritikou I, Calhoun SL, Liao D, Bixler EO. Natural history of excessive daytime sleepiness: role of obesity, weight loss, depression, and sleep propensity. Sleep. 2015;38(3):351-360. doi:10.5665/sleep.4488

39. Liu C, Kong XZ, Liu X, Zhou R, Wu B. Long-term total sleep deprivation reduces thalamic gray matter volume in healthy men. Neuroreport. 2014;25(5):320-323. doi:10.1097/WNR.0000000000000091
40. Tzourio-Mazoyer N, Landeau B, Papathanassiou D, et al. Automated anatomical labeling of activations in SPM using a macroscopic anatomical parcellation of the MNI MRI single-subject brain. Neuroimage. 2002;15(1):273-289. doi:10.1006/nimg.2001.0978

41. Maldjian JA, Laurienti PJ, Kraft RA, Burdette JH. An automated method for neuroanatomic and cytoarchitectonic atlas-based interrogation of fMRI data sets. Neuroimage. 2003;19(3):1233-1239. doi:10.1016/S1053-8119(03)00169-1

42. Dijk DJ, Groeger JA, Stanley N, Deacon S. Age-related reduction in daytime sleep propensity and nocturnal slow wave sleep. Sleep. 2010;33(2):211-223. doi:10.1093/sleep/33.2.211

43. Mansson KNT, Cortes DS, Manzouri A, Li TQ, Hau S, Fischer H. Viewing Pictures Triggers Rapid Morphological Enlargement in the Human Visual Cortex. Cereb Cortex. 2019.

44. Critchley HD, Wiens S, Rotshtein P, Ohman A, Dolan RJ. Neural systems supporting interoceptive awareness. Nat Neurosci. 2004;7 (2):189-195. doi:10.1038/nn1176

45. Soloff P, Nutche J, Goradia D, Diwadkar V. Structural brain abnormalities in borderline personality disorder: a voxel-based morphometry study. Psychiat Res. 2008;164(3):223-236. doi:10.1016/j. pscychresns.2008.02.003

46. Petrovic P, Ekman CJ, Klahr J, et al. Significant grey matter changes in a region of the orbitofrontal cortex in healthy participants predicts emotional dysregulation. Soc Cogn Affect Neurosci. 2016;11 (7):1041-1049. doi:10.1093/scan/nsv072

47. Petrovic P, Castellanos FX. Top-Down Dysregulation-From ADHD to Emotional Instability. Front Behav Neurosci. 2016;10:70. doi:10.3389/fnbeh.2016.00070

48. Rogers JC, De Brito SA. Cortical and Subcortical Gray Matter Volume in Youths With Conduct Problems: a Meta-analysis. JAMA Psychiatry. 2016;73(1):64-72. doi:10.1001/jamapsychiatry.2015.2423

49. Tagliazucchi E, von Wegner F, Morzelewski A, Borisov S, Jahnke K, Laufs H. Automatic sleep staging using fMRI functional connectivity data. Neuroimage. 2012;63(1):63-72. doi:10.1016/j. neuroimage.2012.06.036
Nature and Science of Sleep

\section{Publish your work in this journal}

Nature and Science of Sleep is an international, peer-reviewed, open access journal covering all aspects of sleep science and sleep medicine, including the neurophysiology and functions of sleep, the genetics of sleep, sleep and society, biological rhythms, dreaming, sleep disorders and therapy, and strategies to optimize healthy sleep.
The manuscript management system is completely online and includes a very quick and fair peer-review system, which is all easy to use. Visit http://www.dovepress.com/testimonials.php to read real quotes from published authors. 